\title{
Essay
}

\section{CUREs During and Beyond COVID-19}

\author{
Alita R. Burmeister, ${ }^{1, \#}$ Katie Dickinson, ${ }^{2}$ and Mark J. Graham ${ }^{1}$ \\ ${ }^{1}$ STEM Program Evaluation \& Research Lab (STEM-PERL), Department of Ecology and Evolutionary Biology, \\ Yale University, New Haven, CT 06420, USA; ${ }^{2}$ Department of Biology, University of Washington, Seattle, WA \\ 98915, USA; \#address correspondence to alita.burmeister@yale.edu
}

Keywords: undergraduate, research, COVID-19, CUREs, interest, communication, identity

\begin{abstract}
Course-based Undergraduate Research Experiences (CUREs) provide active and authentic scientific involvement to tens of thousands of students each year. Through this process, CUREs offer the benefits of increased learning outcomes, improved equity, and increased retention in STEM. During the COVID-19 pandemic, however, research and teaching labs have limited capacity. Some universities are closed for in-person learning altogether, and others are likely to face emergency shut-downs throughout the year. In this setting, the inability to conduct experiments limits a core aspect of CUREs. Without experimentation as a basis for student engagement, interest, and broader relevance, true coursebased research this year becomes a major challenge. We suggest that this limitation provides a moment to enhance CUREs with research-enriching learning activities that are obtainable while away from the bench. In this essay we outline a variety of these student-centered activities and review their benefits in terms of student interest, learning, and equity. While useful during emergency teaching transitions during COVID-19, we make the case that these new evidence-based practices for CUREs will also be helpful for the enrichment of research-based learning beyond the current crisis.
\end{abstract}

\section{INTRODUCTION}

In the time of COVID-19, teaching labs have limited capacity, some universities are closed for in-person learning altogether, and many CURE instructors are asking: without benches to work at, how will students learn to do experiments? We have heard instructors propose everything from providing students with virtual labs to running socially-distanced in-person labs or even doing experiments for their students. This continued focus on doing experiments seems to be anchored in traditional lab pedagogies where the main activities are learning techniques, often through particular experiments whose answers are already known. Nevertheless, unless a course already involves computational science that can be more easily done online (Basalla et al., 2020; Jordan et al., 2014; Kirkpatrick et al., 2019; Sikora et al., 2020; Smith et al., 2016) or colleges and universities find ways to remain open without outbreak-related disruptions, the experimentation focus of many existing CUREs will not likely be a sustainable option in many courses.
Until students and instructors can be safely back at the lab bench, we offer the view that there is a world of interest-leveraging, STEM-identity building, and professionally-focused learning objectives tha students can work towards in the meantime. Indeed, even professional scientists have shifted to other research activities while their labs have been restricted or temporarily closed due to the pandemic. So, rather than trying to recreate bench-based experiments online, existing CUREs during COVID-19 should offer a place for students to have meaningful experiences with other scientific practices. When these scientific practices are learned through evidence-based activities, our view is that CURE students will be able to build upon their own interest while learning skills that are important to conducting authentic research and developing as professionals.

For two authors of this essay (ARB and KD), our viewpoint is both as CURE instructors and researchers, and we all have experience in a variety of instructional 
A. R. Burmeister et al.

and professional contexts. ARB has designed and taught a small-scale CURE that incorporates her microbiology and evolution research into the classroom for first- and second-year undergraduates. Her interests include understanding how CUREs can prepare students for future STEM-related careers outside of academia. Before graduate school, she worked as a microbiologist for six years at a large company doing product and process development. KD has been a research scientist at the University of Washington for over 9 years. She helped develop a large-scale CURE that was piloted in an introductory biology series reaching over 600 students. She is interested in the potential of CUREs to engage the whole student, connecting scientific learning and thinking with professional development and equity issues. The third author, $\mathrm{MG}$, comes from a background in educational psychology with an interest in the mechanisms by which CUREs improve student learning and outcomes, particularly those that increase student interest, buy-in, and trust.

The purpose of this essay is to first highlight the many non-experimental ways undergraduate research experiences provide students with valuable skills, and then to propose that these skills be a starting point for new learning objectives and backwards-design of learning activities in CUREs - both during and beyond this pandemic. That is, in thinking through how these activities would work in our own courses and those of others, it has brought about the realization that many of these activities would fit well into CUREs over the long term, even beyond COVID-19. Together with our usual foci of experimentation, project planning, and data analysis, these activities can enrich an overall research experience while building inclusive classrooms and better preparing students for careers in STEM and related fields. These topics would fit well into many research-based courses, and they can provide opportunities for student-centered, collaborative learning. In particular, we integrate three nonexperimentational research pedagogies: 1) leveraging student interest by addressing broader relevance; 2) developing both formal and informal professional communication skills; and, 3) building STEM identity.

\section{RESEARCH-BASED LEARNING AWAY FROM THE BENCH}

Course-based undergraduate research experiences (CUREs) have been proposed and used as a means to increase retention in STEM while also reducing opportunity gaps between well- and under-represented groups (Auchincloss et al., 2014). CUREs are often centered around semester-long research projects in which students collaboratively work on scientific questions of broad relevance; throughout the semester, students seek novel discoveries, often iterating their work during trouble-shooting and replication (Corwin et al., 2018). CURE students frequently demonstrate their knowledge through scientific presentations, writing, or other projects. In many CUREs, students use wet-lab scientific practices as a core tool to do experiments.

In addition to experimentation-based skills, many CUREs also include non-experimentation skills that are important to authentic research. For example, CURE students frequently come up with their own hypotheses, design their own experiments, and are encouraged to view their work as contributing to science more broadly. Furthermore, this ownership over project components is enriched when students collaborate with others and are responsible for communicating their work (Auchincloss et al., 2014). Indeed, many CURE components are akin to scientific teaching principles like active learning, formative assessment, and inclusive teaching practices, thus offering the benefits of increased learning outcomes, improved equity, and increased retention in the sciences (Bransford et al., 2000; Freeman et al., 2014; Miller et al., 2008; Theobald et al., 2020).

In many courses that normally run as CUREs, emergency online instruction related to COVID-19 could mean that experiments will be replaced with background content, journal article reading, computerbased educational simulations, and other activities. While some of these activities are part of the overall research process, they lack the proximity to and authenticity of research normally offered by CUREs. For these experimentation-adjacent classroom activities, instructors can add in supplemental activities to build the skills required to be a professional scientist. In the following sections, we suggest three approaches that instructors might consider during and beyond the COVID-19 crisis. Within each general recommendation area, we present specific options and a guide for what to do, how to do it, and why it helps.

\section{Recommendation \#1: Build Student Interest.}

The current pandemic and how our society's response to it are major reasons to reinforce students' current interest in science. That is, the discovery of a novel 
virus, the rampant news coverage of science and scientific politics, and the direct impact on students' lives, families, and livelihoods provides a direct link between classrooms and students' lives. Because of this, incoming and current students likely have increased attentiveness to science. This attention might be strongest towards biology, but also epidemiology and associated disciplines of mathematics and computer science, as well as STEM more generally. Since ethnic and racial minorities in the US are at a higher risk for COVID-19; therefore, science classes might increase in priority for underrepresented minority (URM) students who could be motivated to use their STEM education to improve public health equity.

As CURE instructors in this pandemic we can leverage student interest to inspire the next generation of scientists and STEM-literate citizens who will be better prepared for the next pandemic, especially in both scientific and social contexts. For example, one of the central hypotheses for why CUREs are effective at engaging and preparing students is that they empower students to contribute directly to broadly relevant scientific questions (Auchincloss et al., 2014; Cooper et al., 2019; Corwin et al., 2018). Different CUREs investigate and generate new knowledge across a wide variety of contexts, from human health through microbiomes (Kirkpatrick et al., 2019), the discovery of new antibiotics (Basalla et al., 2020), the characterization of new viral genomes (Jordan et al., 2014), and the prevalence of antibiotic resistance (Genne-Bacon \& Bascom-Slack, 2018). The more instructors can pair student learning with topics relevant to students' lives or research, the more CUREs might provide motivation for learning and increase students' interest, confidence, persistence, and ownership (Cooper et al., 2019; Graham et al., 2013). Even outside of a direct research experience, interest or perceived usefulness may lead to increased retention in STEM (Hecht et al., 2019).

The problem is that without experimentation during the pandemic, many CURE instructors may be left with just the scientific content of the course - which is less exciting than when this content is covered alongside scientific discovery. During this time, instructors can turn to leveraging other sources of student interest. Many students arrive at a course with pre-existing interest in the course topic, which is positively associated with topic mastery goals and negatively associated with work and performance avoidance goals
(Harackiewicz et al., 2008). Beyond this, establishing situational interest, or relevance, for course scientific content through other means is important for increasing engagement in a course and its associated STEM major (Hanauer et al.; Harackiewicz et al., 2008). Ideally, when students see the relevance of their learning, their overall (personal) interest will also be increased. Relevance can be established in many ways that may appeal differently to individual students. Belova et al. (Belova et al., 2017) identify four categories of scientific relevance, and we use this framework to discuss various ways utility value can be established with respect to CURE content (Table 1).

In courses that suddenly have a focus shifted away from the scientific process due to COVID-19 and the switch to online learning, instructors might be turning to textbooks, lectures, journal article discussions, computer-based simulations, and other activities that lack the authenticity of primary research. To make these more content-heavy courses more relevant and interesting, we next present the following options and activity outlines to help instructors identify options that may work for their courses.

Student-generated relevance and interest. All students have different backgrounds and interests with varied career goals, so they will likely have different points of interest for course material. Facilitating students to identify their unique interests can be an efficient and student-centered approach.

\section{- What to do:}

oWhen focusing on content learning, prompt students to construct their own relevance using utility-value interventions. During utility-value interventions, students answer open-ended prompts through the writing of mini essays, where they link their own learning to topics relevant to either themselves or a friend/family member (Harackiewicz et al., 2008; Priniski et al., 2019).

\section{- How to do it:}

oIn the current environment, students might be further prompted to apply their course thinking to the pandemic with a utility-value intervention specifically targeted to COVID-19 disruptions.

o Some students will be acutely experiencing the pandemic (e.g. through death of a loved one, loss of a job, personal illness, etc.) so doing COVID-19 related activities may be overwhelming. We suggest that instructors consider including a non- 
A. R. Burmeister et al.

COVID-19 option, perhaps related to another public health issue.

- Why it will help:

oA utility-value intervention might help increase equity and inclusion by giving students a variety of options for constructing their own value (Rosenzweig et al., 2019) (Table 1). For example:

- Some students might be more interested in STEM content and the pandemic as a path to future employability (Table 1, A).

- Others might be motivated by innovation and want to find ways to combat this and future pandemics (Table 1, B).

- The pandemic has also highlighted a serious problem in scientific literacy and the way that scientific information and methods are portrayed in mainstream and social media. During COVID19 many students might be attracted to STEM as a way to increase media literacy for themselves and others (Table 1, C).

- Finally, students might be motivated by global health issues, and opportunities abound to link scientific knowledge to policy (Table 1, D).

- Opportunities for education research:

o Testing how specific-context (e.g., COVID-19) utility-value intervention improves student outcomes compares to more open-ended utilityvalue interventions would be an interesting area of study in the coming pandemic and post-pandemic years. From the existing literature, leveraging interest is directly beneficial to individual students, as student interest is positively associated with learning outcomes. In one study, students who made links between their course content and their utility value (relevance) had higher grades in the course and increased persistence in their biology program and major (Canning et al., 2018).

Instructor-guided utility generation. In contrast to student-centered relevance ideas, relevance can also be established in a more instructor-guided way. Instructors might use a combination of traditional instruction and active practices to convey relevance and build interest:

- What to do:

$\circ$ Weave relevant topics and applications into lecture or video materials.

- How to do it:

o Such approaches would be most beneficial when done with active learning exercises dispersed within a lecture, for example, having students reflect on relevance and their own interest through think-pair-share, small group discussions, or 'clicker' type polls (Freeman et al., 2014; Theobald et al., 2020).

o This option would be most useful when students are unlikely to have the expertise required to generate utility relevant to future science careers and applications. While content will be unique to an individual instructor's interests, student populations, and course content, some examples could include:

- Linking antibiotic resistance (Basalla et al., 2020; Genne-Bacon \& Bascom-Slack, 2018) to how COVID-19 might present with bacterial coinfections.

- Relating concepts in phage discovery (Jordan et al., 2014) to the discovery and characterization of novel emerging pathogens, such as COVID-19.

- Demonstrating how math and computer science topics allow large-scale epidemiological modeling.

- Cover a variety of interest-areas (Table 1) to appeal to different students' latent interests.

- Why it will help:

o Instructor-guided relevance is important because beginning learners might not yet have the cognitive skills to draw complex connections among and across topics (Bransford et al., 2000; Moss et al., 2006).

- Opportunities for education research:

$\circ$ Does expert-provided utility on complex topics help student performance in the classroom? Laboratory research suggests that for a simple concept (mathematical multiplication) providing "every-day" utility (e.g., calculating tips) to participants resulted in lower performance (Canning \& Harackiewicz, 2015) than when participants generated their own utility (Option 1A above). Research on whether this effect is generalizable - for example, in a field experiment with utility provided on complex concepts requiring expertise (as in the examples above) will be important for understanding the conditions under which provided-utility helps student performance in CUREs.

Collaborative instructor-student learning through case-based activities. During a typical CURE, students obtain their own data and results to analyze and discuss with peers and instructors. This process can involve learning to work with data, interpreting controls, diagnosing when experiments do not go as expected, 
planning next steps, communicating results and ambiguities, and debating conclusions with others. In the absence of students' own data during nonexperimentation semesters, case-based activities can provide students with authentic scientific questions, experimental design details, resulting data sets, and prompts to think like a scientist while analyzing the case.

\section{- What to do:}

o Add a case-based activity as a substitution for the data analysis, critical thinking, and communication activities CURE students normally encounter as part of their authentic research.

- How to do it:

- Many case studies are readily available for free use, in particular through the National Center for Case Study Teaching in Science (NCCSTS) searchable database (https://sciencecases.lib.buffalo.edu/) (freely accessible with additional instructor guides available for $\$ 25 /$ year). Other, smaller case study sets that have been more closely studied and are entirely freely available, including Data Nuggets (http://datanuggets.org/) and Evo-Ed Cases (http://www.evo-ed.org/).

- For example, the NCCSTS search for cases made for beginner undergraduate students on the specific topic of microbiology and involving data analysis yielded 15 search results. Illustrative examples include: A) The case of the CDC's faulty SARS-CoV-2 test through a researcher's point of view and hypothetical data (Amy C. Groth, Case ID \#1122, https://sciencecases.lib.buffalo.edu/collection/de tail.html/?case $\mathrm{id}=1122 \& \mathrm{id}=1122$ ), and B) A case on the use of phage therapy on nonconsenting populations in the 1920s (Dustin Eno and Annie Prud'homme-Genereux, Case ID \#608,

https://sciencecases.lib.buffalo.edu/collection/de tail.html?case $\mathrm{id}=608 \& \mathrm{id}=608$ ).

o Although more time-consuming to write and implement than off-the-shelf activities, instructors might also develop their own case studies using real data and examples from previous semesters of their CUREs.

- Why it will help:

- Case-based learning is inherently active as it requires students to process information, analyze it, and make predictions, so cases likely offer the benefits of active learning approaches and specifically improve performance and selfassessment (Bonney, 2015).

- Case-based instruction has long been used in medical education to improve context-specific critical thinking and involvement (Thistlethwaite et al., 2012).

- In the context of CUREs, case studies can be designed or adapted to meet course-specific learning objectives, such as technical skills, statistical analysis, data interpretation, and help students build technical skills, for example data interpretation and analysis-- skills central to usual CURE-based learning.

o Some instructors might use their own data from their non-course research programs or previous semesters.

\section{Teaching Recommendation \#2: Develop Authentic Communication Skills.}

Communication is a uniquely powerful skill. It is not only important on its own, but it can also reinforce the acquisition of new knowledge, development of expertise, and strengthening of other scientific competencies. Communication includes a diverse array of written and verbal modes that vary from formal to informal (Table 2). However, CUREs and many traditional labs often focus mostly on formal communication via the usual lab reports and presentations. What we discuss here is the development of other types and contexts of communication - in particular informal communication - as an opportunity to better prepare students for any future career. For our recommendations around formal communication, see Supplementary Materials. While important to academia, informal communication is also especially valued in industry, where teamwork and professionalism are foci of performance reviews and management. Importantly, learning and performance of both formal and informal communication skills can be readily evaluated using authentic assessments through communication products created by students (Brownell \& Kloser, 2015; Gulikers et al., 2004; Zewail-Foote, 2020). 
A. R. Burmeister et al.

Table 1. Category of scientific relevance, importance during COVID-19, and examples in CUREs.

\begin{tabular}{llll}
\hline \multicolumn{1}{c|}{ Category $^{\text {a }}$} & \multicolumn{1}{c}{ Definition } & \multicolumn{1}{c}{ Importance During COVID } & Importance for CURE Students \\
\hline A - Employability & $\begin{array}{l}\text { Gaining skills for further } \\
\text { education and eventual } \\
\text { employment }\end{array}$ & $\begin{array}{l}\text { Preparing future scientists, clinical } \\
\text { laboratory technicians, and health-care } \\
\text { providers }\end{array}$ & $\begin{array}{l}\text { Demonstrating laboratory, analytical, } \\
\text { and communication skills }\end{array}$ \\
\hline B - Innovation & $\begin{array}{l}\text { Suggesting improvements } \\
\text { to authentic issues in a } \\
\text { field of practice outside of } \\
\text { coursework }\end{array}$ & Inventing new therapies and vaccines & $\begin{array}{l}\text { Contributing work that has broad } \\
\text { relevance and novelty }\end{array}$ \\
\hline C - Media literacy & $\begin{array}{l}\text { Understanding and } \\
\text { generating media content }\end{array}$ & $\begin{array}{l}\text { Addressing misrepresentation of } \\
\text { scientific knowledge, expertise, and } \\
\text { process in mainstream and social media }\end{array}$ & $\begin{array}{l}\text { Understanding and generating primary } \\
\text { literature; communicating work to a } \\
\text { broad audience }\end{array}$ \\
\hline D - Sustainability & $\begin{array}{l}\text { Development of } \\
\text { responsible global citizens } \\
\text { and professionals }\end{array}$ & $\begin{array}{l}\text { Combining scientific and policy } \\
\text { knowledge to address a global pandemic }\end{array}$ & $\begin{array}{l}\text { Understanding the social context of } \\
\text { one's work or course content; conducting } \\
\text { ethical research and course work }\end{array}$ \\
\hline
\end{tabular}

adapted from (Belova et al., 2017).

Informal written communication. Informal written communication includes a variety of skills that are not typically assigned in undergraduate curricula (Table 2). These skills are important to development as professionals in the STEM and related disciplines.

- What to do:

- Assign students informal scientific writing that has practical value for science careers.

- Examples of how to do it:

o Have students draft an email of interest to a research principal investigator (PI) asking about undergraduate research in the lab. The activity should include researching potential PIs by reading their websites or research articles.

o Use the communication tools actually used by professionals, such as email and Slack . Rather than sticking to the learning management system, prompt students to start and respond to discussion topics in the forms professionally used in your discipline.

o Assign students to write an email asking for a letter of recommendation. Not only could this assignment involve practicing correspondence with a professor, but it could also include other useful skills: 1) researching potential application opportunities that require letters, such as fellowships, jobs, and internships, and 2) reading example letters of recommendation so students become familiar with the types of behaviors that are rewarded by strong recommendations.

- How to provide feedback:
- Assess these activities using guidelines or a rubric. Give students useful feedback that will help them when they need to use these skills outside of class. $\circ$ Instructors might assign a series of activities like the ones above or on other topics (Table 2), or they might have one focal assignment in which students can choose options most relevant to their individual needs and goals. Providing opportunities for feedback and subsequent revision can also build confidence and make these activities even more useful.

- Why it helps:

o Students from nonacademic backgrounds may not be familiar with the culture of academia and its forms of informal communication. Practice with informal writing, in a safe classroom setting, may help decrease feelings of intimidation and increase confidence. For example, in our own experience, our CURE students might have had a great experience in class but then they simply don't know how to email professors asking for lab positions. Students will only be able to persist if they are able to make it to the next step.

- Informal written communication skills can be evaluated with authentic assessments - that is, the writing of these products themselves. Since these authentic assessments call upon students to write about their own individual interests and goals, they encourage original work, which also promotes academic integrity (Sotiriadou et al., 2019). 
Table 2. Authentic modes of communication that can be turned into assignments and assessments for building professional identity, competence, and confidence. Here, we use the term "formal" to mean either communication intended for a more permanent record or communication that requires advanced preparation. For a suggestion guide for Formal Communication, see the Supplementary Materials.

Formal Communication

Informal Communication

\begin{tabular}{|c|c|c|}
\hline Written & $\begin{array}{l}\text { - } \text { Research manuscripts } \\
\text { - } \text { Review articles } \\
\text { - } \text { Patents } \\
\text { - } \text { Technical reports within a company } \\
\text { - Research proposals } \\
\text { - } \quad \text { Persoarch statements } \\
\text { - } \text { Diversity statements } \\
\text { - Published articles for the scientific public } \\
\text { - } \quad \text { Conference abstracts } \\
\text { - Poster content }\end{array}$ & $\begin{array}{l}\text { - Requesting a recommendation letter; } \\
\text { - } \quad \text { gmailing a PI with interest of joining their lab } \\
\text { - Sending a cover letter with a resume for a job } \\
\text { application; } \\
\text { - Sharing scientific ideas over email } \\
\text { - } \quad \text { Posting scientific information to social media } \\
\text { Responding to others on social media }\end{array}$ \\
\hline
\end{tabular}

Verbal - Scientific presentations

- Behavioral job interviews ${ }^{1}$

- Interviews for the news or podcasts

- Presidential press conferences

- Some chalk talks
- Peer discussions, debates, and explanations

- Chalk talks, depending on the context

- Elevator pitches

- Attending lab meetings

- Visiting office hours

- Informational interviews

- Asking questions at scientific seminars

- Addressing workplace issues (e.g. "Who keeps leaving the lab freezer door open?")

\footnotetext{
'Behavior-based interview questions are widely used in industry and healthcare to assess how candidates interact socially with others. Many question lists are readily available on the internet and include questions relevant to CURE experiences, such as "Tell me about a time you faced failure and how you dealt with it," and "Give me an example of a time a team or group you were on disagreed on an approach and how you handled it."
}

Informal verbal communication. As a collaborative endeavor, scientists need to communicate with their peers, mentors, and mentees about a wide variety of scientific thoughts, processes, and arguments. For example, researchers talk with their lab groups for feedback on results, mentees discuss experiments with their mentors, and lab members communicate about who does lab chores. These vital conversations all take place informally (Table 2). The collaborative nature of many CUREs provides students with an excellent opportunity to hone their informal scientific discussion skills that go beyond just working in groups.

- What to do:

o Build informal verbal communication into the course structure.

- How to do it:

- Organize students into mini lab groups to meet at the beginning of each lab period to discuss their most recent research aims or learning objectives and the successes and failures encountered while addressing them.

o Hold journal club style class meetings by discussing papers related to students' research or course content.

o For assessment, use formative feedback to students with examples of especially effective communication, plus perhaps some percentage of participation points.

- In our experience, one aim of working on these skills is to help students develop comfort and confidence while "learning out loud", which can be undermined by pressure to perform (for example, when being evaluated for credit).

- Why it helps:

○ When working collaboratively, students can solve problems and practice verbalizing their thought process. 
A. R. Burmeister et al.

o These peer discussions, debates, and explanations can help students understand difficult concepts even when the members of the group are naïve (Deslauriers et al., 2011; Smith et al., 2009).

o Encouraging students to talk can increase students' engagement and interest, promote student thinking, and facilitate learning (Tanner, 2009).

\section{Informal and formal written communication}

(Supplementary Material). Although formal writing is often incorporated into CUREs and traditional labs, it is often limited to writing lab reports and presenting final projects. In our Supplementary Discussion we provide recommendations on authentic communication that involves writing for the general public, crafting diversity statements, preparing for job interviews, and giving summative presentations and press conferences.

\section{Teaching Recommendation \#3: Build STEM Student Identity and Sense of Belonging.}

Because many undergraduate students leave STEM programs, with URM students leaving at higher rates (Chen \& Soldner, 2013), one goal for CUREs is to increase persistence in the sciences (Corwin et al., 2015). One factor that can deter persistence is a lack of science identity, which refers to the ability to see oneself as a scientist and is linked to a sense of self-efficacy (Robnett et al., 2015). While identity has many factors, here we focus on how it can be strengthened by having students learn about diverse scientists and developing students' awareness of mentorship norms. For instructorcentered tips on building every-day inclusivity, see Box 1.

Learning about diverse scientists' lives and research. Lack of diversity can leave URM students feeling isolated, so finding ways to increase diverse perspectives with outside resources can be especially useful.

- What to do:

- Assign readings about scientists alongside those scientists' peer-reviewed research manuscripts.

- How to do it:

oHighlight researchers whose topics relate to the course.
○Use pre-existing material for easy implementation. Options include:

- a) "Science Spotlights" (https://scientistspotlights.org/) which provide students with counter-stereotypical examples;

- b) "Skype a Scientist"

(https://www.skypeascientist.com/) which connects scientists to classrooms; and

- c) Podcasts, YouTube videos, Story Colliders, and Ted Talks. For a great starting example listen to Brandon Ogbunu's personal story about about undergraduate research and racism in science, "Liberation of RNA"

(https://www.wnycstudios.org/podcasts/radi olab/articles/liberation-rna).

- Why it helps:

oStereotypes of scientists, both positive and negative, may influence a student's sense of belonging in STEM (Cheryan et al., 2013; Schinske et al., 2016).

oProviding assignments that featured diverse scientists reduced descriptions of scientist stereotypes, which were correlated with increases in science interest (Schinske et al., 2016).

Learning about mentee roles. Although developing mentoring relationships is out of scope for most CUREs, our classrooms can still be a place where students learn about mentee benefits, boundaries, and responsibilities. With this knowledge, students will be better informed about what to expect when later pursuing research outside of class.

- What to do:

- Have students read and analyze existing mentoring compacts (also called a mentormentee agreements), which describe research expectations and facilitate mentoring, or

- Have students read examples of (or write their own) individual development plans (IDPs) to learn about science careers, to identify their own values and interests, and to assess their skills. 


\section{BOX 1. INCLUSIVE CLASSROOM PRACTICES}

Instructors can strive to improve STEM identity and a sense of belonging by bringing diversity into the classroom. While most of our recommendations have been student-centered, in this box we put the focus on instructors' use of language and practices that demonstrate inclusivity. These practices can be used every day in all classroom activities.

- What to do:

$\circ$ Read up on inclusive language and use it.

- If you already use inclusive language, refresh yourself on the latest -- insights and norms change regularly

- How to do it:

$\circ$ Check out LSE's Evidence-Based Inclusive Teaching guides (https://se.ascb.org/evidence-based-teachingguides/inclusive-teaching/) (Dewsbury \& Brame, 2019).

$\circ$ Use diverse examples that include primary research and personal accounts from scientists at Project BioDiversify (https://projectbiodiversify.org/).

○ Sharpen up on your gender-inclusive language and be aware of how gendered language may impact learning of course concepts, which is especially important in many biological disciplines (Hales, 2020) (https://genderinclusivebiology.squarespace.com/).

o Learn and pronounce all of you students' names (Tanner, 2013).

- Why it helps:

○ Building an inclusive and supportive classroom is thought to enhance a student's sense of belonging and self-efficacy, which are then linked to increase achievement and motivation (Dewsbury \& Brame, 2019; Tanner, 2013; Zumbrunn et al., 2014).

○ Using deliberate and inclusive language when discussing biology and genetics topics relevant to gender identity, disability, and race can remove outdated, stereotyping terminology (Hales, 2020)

$\circ$ With remote learning, students and instructors can feel isolated. It may be more important now than ever for instructors to be respectful, warm, and inclusive.

- How to do it:

$\circ$ Provide students with examples, such as:

- Mentoring compacts from the UW Institute for

Clinical and Translational Research) (https://ictr.wisc.edu/mentoring/mentoring\%20compactscontracts-examples/)

- Undergraduate IDPs from the APS (https://www.aps.org/programs/minorities/nmc/u pload/UndergradResearcherIDP.pdf). APS also has a great general undergraduate mentee site and mentorship program

(https://www.aps.org/programs/minorities/nmc/ webinars.cfm)

- Articulate the goals of a research mentoring relationship, perhaps examples that you use with your students or that you had when you were a mentee.

o Discuss why a compact or IDP might be useful.

o Normalize the idea that it is good for students to ask their mentors for information, help, and structure. Use example compact and IDPs to prompt students to think about questions they can ask during interviews or once they become a mentee.

- Why learning about mentoring helps: o Students learn about the social structure, behavior norms, and expectations of a scientific community (Balster et al., 2010).

- Mentoring tools can help improve communication skills and interactions resulting in improved research skills, increased confidence, and reduced conflict (Byars-Winston et al., 2019).

$\circ$ Mentoring increases undergraduate success in STEM (Linn et al., 2015).

oStructured mentoring in this way can level the playing field, helping to give all students knowledge, skills, and confidence they need to find an undergraduate research position and/or a job outside of academia.

\section{CONCLUSION}

Improving course design in terms of student interest, equity, and evidence-based practices is always important, but COVID-19 has created a time to reassess these features while our normal classroom activities are disrupted. In particular, the student-centered learning focus of CUREs can, at this moment of transition to online learning, include leveraging interest in STEM, developing professional communication skills, and building STEM identity. During these challenging 
A. R. Burmeister et al.

semesters ahead where CUREs remain largely online, we hope that CURE instructors will continue to advance their own knowledge, to try new things in the classroom, and to facilitate learning and inspiration in the current generation of CURE students. Beyond COVID-19, we anticipate that some of these temporary additions might be useful stepping stones to build longer-term course changes, similar to work that shows short-term research experiences can lead to semester-long research courses (Genne-Bacon et al., 2020).

Compared to courses that can continue their contentbased instruction remotely, CUREs are uniquely situated to include alternative activities. CURE instructors may have freed up class time and are likely accustomed to ambiguous situations and needing to change course. However, all CUREs are different, and we also encourage instructors to consider their student population's needs, as well as their own instructor needs. For example, some CURE courses may need to cover specific topics to prepare students for technical careers. With the activities we have proposed in this essay, we have aimed to identify evidence-backed "drag and drop" activities that can fit well into suddenlydisrupted CURE courses. We also propose that such activities will be more useful to student learning and engagement the more that they are interconnected, similar to the research arc of activities students normally encounter in CUREs (Auchincloss et al., 2014; Corwin et al., 2015). Whether implemented individually or as a group of activities, we stress that using backwards design with a focus on learning objectives will be the best way to guide course design around student needs (Cooper et al., 2017). Instructors should consider our suggestions as a starting point to identify new learning objectives, then build from there to incorporate new learning activities.

It is also important to emphasize that there is still a fundamental difference between CUREs and nonexperimentation courses. Ongoing research aims to identify the essential components of CUREs for student learning, and we view experimentation and research authenticity as key components in that process. There is something powerful about students being responsible for carrying out their own experiments, needing to repeat failures and develop grit, and having the potential to be able to contribute truly novel results to the world. Towards that end, we hope that some of the ideas presented here will enable future CURE students' scientific experiences. Meanwhile, even during these isolating times due to COVID-19, building studentstudent and student-instructor relationships through repeated practice with authentic activities and feedback on performance will enable students to make meaningful connections and start them on the path of scientific research.

\section{ACKNOWLEDGMENTS}

We thank the NSF RAPID program for funding (grant \#20276598) and the HHMI Campus Grant at Yale University (grant \#52008128). We thank Mike Blazanin and Scott Freeman for useful comments on an earlier version of the manuscript.

\section{REFERENCES}

Auchincloss, L. C., Laursen, S. L., Branchaw, J. L., Eagan, K., Graham, M., Hanauer, D. I., ... \& Dolan, E. L. (2014). Assessment of course-based undergraduate research experiences: a meeting report. CBE Life Sci Educ, 13(1), 29-40. https://doi.org/10.1187/cbe.14-01-0004

Balster, N., Pfund, C., Rediske, R., \& Branchaw, J. (2010). Entering research: a course that creates community and structure for beginning undergraduate researchers in the STEM disciplines. $C B E$ Life Sci Educ, 9(Summer 2020), 108-118.

Basalla, J., Harris, R., Burgess, E., Zeedyk, N., \& Wildschutte, H. (2020). Expanding Tiny Earth to genomics: a bioinformatics approach for an undergraduate class to characterize antagonistic strains. FEMS Microbiol Lett, 367(1). https://doi.org/10.1093/femsle/fnaa018

Belova, N., Dittmar, J., Hansson, L., Hofstein, A., Alexis, J., NielsenJesper, \& Eilks, S. (2017). Cross-curricular goals and raising the relevance of science education. contributions from science education research, vol 3. Springer, Cham. . In J. K. Hahl K., Lampiselkä J., Uitto A., Lavonen J. (eds) (Ed.), Cognitive and Affective Aspects in Science Education Research. https://doi.org/10.1007/978-3-319-58685-4_22

Bonney, K. M. (2015). Case study teaching method improves student performance and perceptions of learning gains. J Microbiol Biol Educ, 16(1), 21-28. https://doi.org/10.1128/jmbe.v16i1.846

Bransford, J., National Research Council (U.S.). Committee on Developments in the Science of Learning., \& National Research Council (U.S.). Committee on Learning Research and Educational Practice. (2000). How people learn : brain, mind, experience, and school (Expanded ed.). National Academy Press.

Brownell, S. E., \& Kloser, M. J. (2015). Toward a conceptual framework for measuring the effectiveness of course-based undergraduate research experiences in undergraduate biology. Studies in Higher Education, 40(3), 525-544. https://doi.org/10.1080/03075079.2015.1004234 
Byars-Winston, A., Dahlberg, M. L., \& National Academies of Sciences Engineering and Medicine (U.S.). (2019). The science of effective mentorship in STEMM. The National Academies Press.

Canning, E. A., \& Harackiewicz, J. M. (2015). Teach it, don't preach it: the differential effects of directly-communicated and selfgenerated utility value information. Motiv Sci, 1(1), 47-71. https://doi.org/10.1037/mot0000015

Canning, E. A., Harackiewicz, J. M., Priniski, S. J., Hecht, C. A., Tibbetts, Y., \& Hyde, J. S. (2018). Improving performance and retention in introductory biology with a utility-value intervention. $J$ Educ Psychol, 110(6), 834-849. https://doi.org/10.1037/edu0000244

Chen, X., \& Soldner, M. (2013). STEM attrition: college students' paths into and out of STEM fields. Statistical analysis report. NCES 2014-001.

Cheryan, S., Plaut, V. C., Handron, C., \& Hudson, L. (2013). The stereotypical computer scientist: gendered media representations as a barrier to inclusion for women. Sex Roles, 69(1-2), 58-71. https://doi.org/10.1007/s11199-013-0296-x

Cooper, K. M., Blattman, J. N., Hendrix, T., \& Brownell, S. E. (2019). The impact of broadly relevant novel discoveries on student project ownership in a traditional lab course turned CURE. CBE Life Sci Educ, 18(4), ar57. https://doi.org/10.1187/cbe.19-06-0113

Cooper, K. M., Soneral, P. A. G., \& Brownell, S. E. (2017). Define your goals before you design a CURE: a call to use backward design in planning course-based undergraduate research experiences. $J$ $\begin{array}{llll}\text { Microbiol Biol Educ, } & \text { 18(2). }\end{array}$ https://doi.org/10.1128/jmbe.v18i2.1287

Corwin, L. A., Graham, M. J., \& Dolan, E. L. (2015). Modeling course-based undergraduate research experiences: an agenda for future research and evaluation. CBE Life Sci Educ, 14(1), es1. https://doi.org/10.1187/cbe.14-10-0167

Corwin, L. A., Runyon, C. R., Ghanem, E., Sandy, M., Clark, G., Palmer, G. C., ... \& Dolan, E. L. (2018). Effects of discovery, iteration, and collaboration in laboratory courses on undergraduates' research career intentions fully mediated by student ownership. $C B E$ Life Sci Educ, 17(2), ar20. https://doi.org/10.1187/cbe.17-07-0141

Deslauriers, L., Schelew, E., \& Wieman, C. (2011). Improved learning in a large-enrollment physics class. Science, 332(6031), 862-864. https://doi.org/10.1126/science. 1201783

Dewsbury, B., \& Brame, C. J. (2019). Inclusive teaching. CBE Life Sci Educ, 18(2), fe2. https://doi.org/10.1187/cbe.19-01-0021

Freeman, S., Eddy, S. L., McDonough, M., Smith, M. K., Okoroafor, N., Jordt, H., \& Wenderoth, M. P. (2014). Active learning increases student performance in science, engineering, and mathematics. Proceedings of the National Academy of Sciences, 111(23), 84108415. https://doi.org/10.1073/pnas.1319030111

Genne-Bacon, E. A., \& Bascom-Slack, C. A. (2018). The PARE project: a short course-based research project for national surveillance of antibiotic-resistant microbes in environmental samples. J Microbiol Biol Educ, 19(3). https://doi.org/10.1128/jmbe.v19i3.1603

Genne-Bacon, E. A., Wilks, J., \& Bascom-Slack, C. (2020). Uncovering factors influencing instructors' decision process when considering implementation of a course-based research experience. CBE Life Sci Educ, 19(2), ar13. https://doi.org/10.1187/cbe.19-100208
Graham, M. J., Frederick, J., Byars-Winston, A., Hunter, A. B., \& Handelsman, J. (2013). Science education. Increasing persistence of college students in STEM. Science, 341(6153), 1455-1456. https://doi.org/10.1126/science. 1240487

Gulikers, J. T. M., Bastiaens, T. J., \& Kirschner, P. A. (2004). A fivedimensional framework for authentic assessment. ETR\&D, 52(3), 67-86.

Hales, K. G. (2020). Signaling inclusivity in undergraduate biology courses through deliberate framing of genetics topics relevant to gender identity, disability, and race. CBE Life Sci Educ, 19(2), es2. https://doi.org/10.1187/cbe.19-08-0156

Hanauer, D. I., Graham, M. J., \& Hatfull, G. F. A measure of college student persistence in the sciences (PITS). CBE Life Sci Educ, 15(4). https://doi.org/10.1187/cbe.15-09-0185

Harackiewicz, J. M., Durik, A. M., Barron, K. E., LinnenbrinkGarcia, L., \& Tauer, J. M. (2008). The role of achievement goals in the development of interest: Reciprocal relations between achievement goals, interest, and performance. Journal of Educational Psychology, 100(1), 105-122. https://doi.org/10.1037/0022-0663.100.1.105

Hecht, C. A., Harackiewicz, J. M., Priniski, S. J., Canning, E. A., Tibbetts, Y., \& Hyde, J. S. (2019). Promoting persistence in the biological and medical sciences: an expectancy-value approach to intervention. $J$ Educ Psychol, 11(8), 1462-1477. https://doi.org/10.1037/edu0000356

Jordan, T. C., Burnett, S. H., Carson, S., Caruso, S. M., Clase, K., DeJong, R. J., ... \& Hatfull, G. F. (2014). A broadly implementable research course in phage discovery and genomics for first-year undergraduate students. mBio, 5(1), e01051-01013. https://doi.org/10.1128/mBio.01051-13

Kirkpatrick, C., Schuchardt, A., Baltz, D., \& Cotner, S. (2019). Computer-based and bench-based undergraduate research experiences produce similar attitudinal outcomes. CBE Life Sci Educ, 18(1), ar10. https://doi.org/10.1187/cbe.18-07-0112

Linn, M. C., Palmer, E., Baranger, A., Gerard, E., \& Stone, E. (2015). Undergraduate research experiences: impacts and

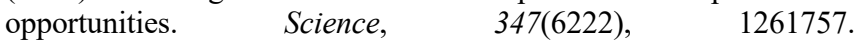
https://doi.org/10.1126/science.1261757

Miller, S., Pfund, C., Pribbenow, C. M., \& Handelsman, J. (2008). Scientific teaching in practice. Science, 322(5906), 1329-1330. https://doi.org/10.1126/science.1166032

Moss, J., Kotovsky, K., \& Cagan, J. (2006). The role of functionality in the mental representations of engineering students: some differences in the early stages of expertise. Cogn Sci, 30(1), 65-93. https://doi.org/10.1207/s15516709cog0000_45

Priniski, S. J., Rosenzweig, E. Q., Canning, E. A., Hecht, C. A., Tibbetts, Y., Hyde, J. S., \& Harackiewicz, J. M. (2019). The benefits of combining value for the self and others in utility-value interventions. $J$ Educ Psychol, 111(8), 1478-1497. https://doi.org/10.1037/edu0000343

Robnett, R. D., Chemers, M. M., \& Zurbriggen, E. L. (2015). Longitudinal associations among undergraduates' research experience, self-efficacy, and identity. Journal of Research in Science Teaching, 52(6), 847-867. https://doi.org/10.1002/tea.21221

Rosenzweig, E. Q., Harackiewicz, J. M., Priniski, S. J., Hecht, C. A., Canning, E. A., Tibbetts, Y., \& Hyde, J. S. (2019). Choose your own intervention: using choice to enhance the effectiveness of a utility- 
A. R. Burmeister et al.

value intervention. Motivation Science, 5(3), 269-276. https://doi.org/10.1037/mot0000113

Schinske, J. N., Perkins, H., Snyder, A., \& Wyer, M. (2016). Scientist spotlight homework assignments shift students' stereotypes of scientists and enhance science identity in a diverse introductory science class. CBE Life Sci Educ, 15(3). https://doi.org/10.1187/cbe.16-01-0002

Sikora, A., Irby, S. M., Hall, B. L., Mills, S. A., Koeppe, J. R., Pikaart, M. J., ... \& Roberts, R. (2020). Responses to the COVID19 pandemic by the biochemistry authentic scientific inquiry lab (BASIL) CURE Consortium: reflections and a case study on the switch to remote learning. Journal of Chemical Education, 97(9), 3455-3462. https://doi.org/10.1021/acs.jchemed.0c00729

Smith, J. J., Johnson, W. R., Lark, A. M., Mead, L. S., Wiser, M. J., \& Pennock, R. T. (2016). An Avida-ED digital evolution curriculum for undergraduate biology. Evolution: Education and Outreach, 9(1). https://doi.org/10.1186/s12052-016-0060-0

Smith, M. K., Wood, W. B., Adams, W. K., Wieman, C., Knight, J. K., Guild, N., \& Su, T. T. (2009). Why peer discussion improves student performance on in-class concept questions. Science, 323(5910), 122-124. https://doi.org/10.1126/science.1165919

Sotiriadou, P., Logan, D., Daly, A., \& Guest, R. (2019). The role of authentic assessment to preserve academic integrity and promote skill development and employability. Studies in Higher Education, 1-17. https://doi.org/10.1080/03075079.2019.1582015

Tanner, K. D. (2009). Talking to learn: why biology students should be talking in classrooms and how to make it happen. CBE Life Sci Educ, 8(2), 89-94. https://doi.org/10.1187/cbe.09-03-0021

Tanner, K. D. (2013). Structure matters: twenty-one teaching strategies to promote student engagement and cultivate classroom equity. $\quad C B E$ Life Sci Educ, 12(3), 322-331. https://doi.org/10.1187/cbe.13-06-0115

Theobald, E. J., Hill, M. J., Tran, E., Agrawal, S., Arroyo, E. N., Behling, S., .. \& \& Freeman, S. (2020). Active learning narrows achievement gaps for underrepresented students in undergraduate science, technology, engineering, and math. Proc Natl Acad Sci US A, 117(12), 6476-6483. https://doi.org/10.1073/pnas.1916903117

Thistlethwaite, J. E., Davies, D., Ekeocha, S., Kidd, J. M., MacDougall, C., Matthews, P., ... \& Clay, D. (2012). The effectiveness of case-based learning in health professional education. A BEME systematic review: BEME Guide No. 23. Med Teach, 34(6), e421-444. https://doi.org/10.3109/0142159X.2012.680939

Zewail-Foote, M. (2020). Pivoting an upper-level, project-based biochemistry laboratory class to online learning during COVID-19: enhancing research skills and using community outreach to engage undergraduate students. Journal of Chemical Education, 97(9), 2727-2732. https://doi.org/10.1021/acs.jchemed.0c00543
Zumbrunn, S., McKim, C., Buhs, E., \& Hawley, L. R. (2014). Support, belonging, motivation, and engagement in the college classroom: a mixed method study. Instructional Science, 42(5), 661684. https://doi.org/10.1007/s11251-014-9310-0 
CURES During and Beyond COVID-19

\section{SUPPLEMENTARY INFORMATION}

\section{Appendix 1: Formal Communication}

In this supplemental discussion, we present options for student learning of formal writing and verbal communication. Although formal writing is often incorporated into CUREs and traditional labs, it is often limited to writing lab reports and presenting final projects. Here, we provide ideas for a variety of communication activities. For additional ideas, see Main Text Table 2.

Formal Writing. Formal scientific writing goes well beyond the usual lab reports that many CUREs and traditional labs require of students (Main Text Table 2). Learning how to write in a variety of contexts is important in both academia (e.g., research proposals, diversity statements, and review articles) as well as in industry (e.g. technical reports and patents).

- What to do:

- Give students authentic formal scientific writing assignments

- How to do it:

○ Create assignments that give students authentic utility (real-life value). Examples include:

- Write course-related content for the general public. Have students summarize research into articles for the general public. The activity could include first reading popular press work (for example, from the Science section of the NY Times), picking a recent research article of interest to the student and related to course content, and having friends or families (as "the general public") offer comments on an early draft. When CUREs resume in person, students could write about their own research for the general public.

- Write a diversity statement. Provide students with a "diversity statement" prompt. That is, diversity statements are used by individual academics to describe the vision and approach to diversity, equity, and inclusion within student work groups. Using a prompt (such as one your university requires for faculty applicants), have students write about their own values as it relates to their scientific interests to draft their own diversity statement. The assignment might also include having students review and contrast diversity statements they find for professors at their own university.

- Instructors might assign a series of activities like the ones above or on other topics (Main Text Table 2), or have one focal assignment in which students can choose options most relevant to their individual needs and goals.

$\circ$ Pair this writing activity to reading and analysis of similar products (e.g., NY Times articles or faculty diversity statements.)

○ Assess the student's work and provide specific feedback and opportunities to revise and resubmit.

- Why it helps:

o Although not immediately an obvious research activity, crafting diversity statements (or diversity-related sections in scholarship prompts) might provide a way for students to reflect on what it means for their own and others' inclusion in STEM. Such reflection could reinforce a sense of belonging and identity needed to persist in the STEM fields. For example, in our own experience, both well- and under-represented students have sought out additional help and clarification on the purpose of diversity statements and content.

- Communication is also associate with more concretely measurable outcomes. Brownell et al. made communication an explicit course goal and found an increase in students' perception of understanding of primary literature and improved confidence in their scientific communication skills (Brownell et al., 2013).

Formal Verbal Communication. While the slide- or poster- based presentation is a mainstay of many CUREs, formal verbal communication also includes occasions that demand quite different skills, including answering questions at job interviews, some chalk talks, answering questions asked by the public or press, and presenting online.

- What to do: 
A. R. Burmeister et al.

o Provide students with synchronous or asynchronous authentic activities that involve preparing different types of verbal communication in advance of an authentic assessment

- How to do it:

- Create assignments that give students authentic practice for professional and other relevant situations (Table 2). Some examples include:

- Job interview scenarios. Have students read about behavioral-based job interviewing and prepare answers for potential answers in the context of your course. For example, if asked about a time they experienced failure and how they handled it, students could discuss instances of experiments not working out, or during remote instruction, how they recovered from a poor quiz or assignment grade. Answers could be submitted as short videos with student answers.

- Summative presentations. Even in the absence of their own research to present on, student presentations can be used as forms of summative assessments in place of exams, the traditional way of assessing student content knowledge. Summative presentations are especially useful in CUREs, where many instructors are accustomed to presentations being the primary mode of final assessment.

- Press conferences. Have students prepare and participate in "press conferences." Have one group of students prepare and deliver a brief presentation on a topic in the news (potentially COVID-19, Section 1.1). Another group of students will answer questions, and a third group will fact-check information given during the Q\&A. This activity can help reinforce scientific knowledge as well as the process of science and how it is portrayed in the media. The activity could also intersect with other skills, involving pre-discussions of news and research articles, picking topics of interest to the students and relevant to the course topics.

- Why it helps:

oLike the other activities suggested in this section, having students plan and execute on formal verbal communication gives them authentic experiences and assessments, which are aligned with the skills they will need in professional life (Gulikers et al., 2004).

\section{Supplemental References}

Brownell, S. E., Price, J. V., \& Steinman, L. (2013). A writing-intensive course improves biology undergraduates' perception and confidence of their abilities to read scientific literature and communicate science. $A d v$ Physiol Educ, 37(1), 70-79. https://doi.org/10.1152/advan.00138.2012

Gulikers, J. T. M., Bastiaens, T. J., \& Kirschner, P. A. (2004). a five-dimensional framework for authentic assessment. ETR\&D, 52(3), 67-86. 